\title{
Periodismo, actores sociales y migración: intertextualidad en los discursos periodísticos sobre migración
}

\author{
Journalism, social actors and migration: \\ intertextuality in journalistic discourses on migration
}

\author{
Eduardo Torre-Cantalapiedra / eduardotorrephd@gmail.com \\ http://orcid.org/0000-0002-4074-3752 \\ Universidad Nacional Autónoma de México, México
}

\begin{abstract}
The objective of this paper is to analyze intertextuality in journalistic discourses regarding migration in transit over Mexican territory. Based on 131 informative texts published between 2012 and 2017 in newspaper "El Universal" and following a mixed methodology - descriptive statistics and qualitative analysis - we analyze how such newspaper refers to the voices of social actors in their texts about Central American clandestine transmigration, according to two contrasting practices: routine journalism and investigative journalism. Likewise, inferences are made about the power that different actors have over and in journalistic discourses, that is, the access they have to these discourses and the control they exert over their characteristics. The voices of the state actors were the most frequently mentioned and in a way that allows us to infer a considerable, but not absolute, power over journalistic discourses.
\end{abstract}

Key words: migration policy, migration in transit through Mexico, Central Americans, critical analysis of journalistic discourse, national press.

Resumen: El objetivo de este trabajo es analizar la intertextualidad en los discursos periodísticos sobre migración en tránsito por el territorio mexicano. Con base en 131 textos informativos, publicados entre 2012 y 2017 en el periódico El Universal y siguiendo una metodología mixta -estadística descriptiva y análisis cualitativo-, se estudia cómo tal diario refiere las voces de los actores sociales en sus textos sobre la transmigración centroamericana clandestina, según dos prácticas contrastantes: el periodismo de rutina y el periodismo de investigación. Asimismo, se realizan inferencias sobre el poder que los diversos actores poseen sobre y en los discursos periodísticos; esto es, el acceso que tienen a estos discursos y el control que ejercen sobre sus características. Las voces de los actores estatales fueron las referidas con mayor frecuencia y de un modo que permite inferir un considerable, aunque limitado, poder respecto a los discursos periodísticos.

Palabras clave: política migratoria, poder, migración centroamericana en tránsito, prensa nacional mexicana. 


\section{Introducción $^{1}$}

Al cubrir la información sobre la migración internacional, los textos periodísticos configuran discursos respecto a la misma: el discurso que (re)presenta a los inmigrantes, esto es, que caracteriza quiénes son "ellos", inmigrantes, respecto a quiénes somos "nosotros", ciudadanos; los discursos sobre la migración en situación irregular o migración clandestina; los discursos sobre el "deber ser" y el "ser" de las políticas y medidas del gobierno en materia migratoria y respecto a los migrantes, entre otros.

El acceso al discurso periodístico se ha considerado un recurso de poder (van Dijk, 1999) y resulta fundamental examinar cuáles son los actores que tienen acceso al mismo y de qué manera. Aunque los discursos periodísticos están bajo el control de periodistas, los actores sociales acceden a ellos de una u otra manera. Por ejemplo, se señala que los medios de comunicación difunden los discursos sobre migración emitidos por actores gubernamentales, discursos considerados hegemónicos/dominantes (Spener, 2008; Bruno, 2010).

En cuanto a cómo las voces de los distintos actores sociales penetran en los discursos de la prensa hay que tener en cuenta dos características fundamentales de la labor periodística: primero, que los textos noticiosos deben reflejar los diferentes puntos de vista de los implicados. En este sentido, cualquier periódico que se precie de ser riguroso, debe tener por norma hablar con todos aquellos implicados en un acontecimiento (Grijelmo, 2014). Segundo, que los actores sociales son generalmente las fuentes de información de los periodistas; por tanto, son esenciales en la construcción de la noticia (Rodrigo-Alsina, 1989).

La forma en que estos discursos periodísticos sobre la migración son producidos y sus contenidos, entre otros aspectos, han sido objeto de numerosas investigaciones en varios países. Así, la literatura académica en torno a esta clase de discursos ha sido especialmente prolija en España, principalmente desde una perspectiva crítica que revela las incongruencias y sesgos presentes en los mismos (Retis, 2004; Nash, 2005; Casero- Ripollés, 2007). Por el contrario, en cuanto a la migración de mexicanos a Estados Unidos, la literatura que analiza los discursos periodísticos en ambos países es escasa, salvo excepciones (Spener, 2008).

Con base en lo anterior, el objetivo de este trabajo es analizar cómo los discursos de la prensa nacional sobre la migración en tránsito por México son

1 Quiero agradecer a la Hemeroteca Nacional de México por su labor de conservación y por poner a disposición material periodístico que permite llevar a cabo investigaciones académicas como la aquí presentada. 
erigidos a partir de las voces de diferentes actores sociales ${ }^{2}$, según la forma como se ejerce la práctica del periodismo. Asimismo, el acceso que la prensa otorga a los discursos de distintos actores sociales y la manera como se refiere a los mismos permite hacer inferencias sobre el poder que tales actores tienen respecto a los discursos periodísticos.

El trabajo está dividido en cuatro secciones. Primero, se presenta la perspectiva teórica sobre intertextualidad que retomamos en este trabajo y la manera en que facilita realizar inferencias. Segundo, se examinan dos formas de hacer periodismo: rutina e investigación (se sigue la tipología de CaminosMarcet, 1997); en particular las implicaciones que estas prácticas tienen en cuanto al tratamiento que se da a las fuentes de información y a los textos periodísticos resultantes.

Tercero, se presenta el corpus de noticias y la metodología mixta que se sigue en este artículo, en el cual se combina: un análisis cuantitativo de frecuencias de ciertas características de los textos informativos, donde se seleccionan algunos de ellos para realizar un análisis cualitativo descriptivo. Cuarto, con base en 131 noticias publicadas en la versión impresa de $E l$ Universal, se examina la manera en que el diario refiere en sus discursos respecto a la migración en tránsito a discursos de otros actores sociales sobre dicha materia. Asimismo, se hacen inferencias sobre el poder que los actores sociales -migrantes, gobiernos, defensores de los derechos de los migrantes, entre otros- tienen en relación con los discursos periodísticos.

\section{Intertextualidad en el discurso periodístico y las relaciones de poder}

La intertextualidad discursiva supone que los textos deben ser entendidos en referencia al conjunto de discursos que les circundan en un determinado tiempo histórico y espacio social.

De acuerdo con la propuesta de intertextualidad de Fairclough (1995), en un discurso concreto se puede analizar la presencia de elementos tomados de otros discursos. La intertextualidad es entendida por este autor como

2 Respecto al discurso sobre la migración centroamericana en tránsito por México se podría decir que los actores sociales a tomar en cuenta son: 1) los migrantes centroamericanos en tránsito clandestino; 2) actores estatales de los países de origen (principalmente, Guatemala, Honduras y El Salvador), de tránsito (México) y de destino (Estados Unidos); 3 ) defensores de los migrantes (religiosos, activistas, casas del migrante, organizaciones de la sociedad civil, instituciones defensoras de los derechos humanos, organismos internacionales, entre otros); 4) la ciudadanía mexicana; 5) los "coyotes" “"polleros"; 6) el crimen organizado; y 7) la academia. 
bricolaje discursivo, el propio discurso de los sujetos se compone de trozos de discursos ajenos (Alonso y Callejo, 1999; Ruiz- Ruiz, 2009). "Lo intertextual queda como un ocasional instrumento al servicio del poder capaz de imponer discursos ajenos en los receptores" (Alonso y Callejo, 1999: 46-47) y "a interpretar los discursos como síntomas de una dominación: los sujetos son reducidos a meros reproductores de discursos dominantes" (Ruiz-Ruiz, 2009: 15).

Por su parte, Genette (1989: 10) retoma el concepto de intertextualidad acuñado por Kristeva (1997) para definirlo de manera restrictiva, "como una relación de copresencia entre dos o más textos, es decir, eidéticamente y con frecuencia, como la presencia efectiva de un texto en otro"; y señala las siguientes formas de intertextualidad: la cita, el plagio y la alusión.

Este trabajo retoma la noción de intertextualidad restringida a la manera de Genette (1989) y la idea de poder y dominación que subyace en la propuesta de Fairclough (1995) por tres razones:

$\left.1^{\circ}\right)$ Los requerimientos de información son mucho menores que en otras perspectivas de la intertextualidad, lo cual se adecua al análisis basado exclusivamente en una recopilación de textos periodísticos.

$2^{\circ}$ ) Por más que se trate de un concepto de intertextualidad acotado, con base en los textos periodísticos, nos permite hacer inferencias respecto a: i) las relaciones de poder sobre el discurso, quién tiene acceso al mismo, esto es, "quién aparece a menudo en los medios de comunicación y, sobre todo, quién goza de una credibilidad suficiente como para que sus declaraciones sean noticia automáticamente" (De la Fuente-García, 2017: 3) y ii) las relaciones de poder en el discurso, esto es, las que se refieren "al control que los actores sociales con acceso al discurso ejercen sobre sus características concretas como pueden ser los temas que se tratan con amplitud o los que reciben escasa atención, la visión que se ofrece de un determinado problema, los presupuestos ideológicos que sustentan el discurso periodístico, etc." (De la Fuente-García, 2017: 3).

$3^{\circ}$ ) No sólo permite dar cuenta de las partes de discurso ajeno a las que se da acceso en el discurso periodístico, sino también analizar el tratamiento que se da a tales pedazos. Por ejemplo, no es lo mismo reproducir los elementos fundamentales de un discurso ajeno, que recuperar sólo fragmentos de menor importancia. En cualquier caso, hay que tener en cuenta que el periodista es quien tiene el control del discurso periodístico y que el proceso de referenciar el discurso ajeno siempre implica la manipulación de los elementos discursivos que recupera por más que se pretenda ser objetivo (MéndezGarcía de Paredes, 2000). En este sentido, el esquema de intertextualidad 
adoptado en el presente artículo se complementa con una tipología de formas en que se ejerce la profesión periodística: el periodismo de investigación y el periodismo de rutina.

\section{El periodismo de rutina frente al periodismo de investigación: los actores sociales como fuentes de información y la migración internacional}

Caminos-Marcet (1997) describe y analiza lo que denomina periodismo de rutina, una forma de ejercer la profesión que supone una actitud pasiva de los periodistas frente a determinadas fuentes de información a las que se cede la iniciativa; esto es, permanecer a la espera de que las instituciones y organismos oficiales les suministren información, y relegar la búsqueda de información con sus propios recursos. Según el mencionado autor, la pasividad acarrea publicar textos sin que estén suficientemente verificados y contrastados.

Asimismo, Caminos-Marcet (1997) señala dos razones por las que los periodistas están adoptando este posicionamiento pasivo: 1) el hecho de que prácticamente la totalidad de los organismos e instituciones dispongan de mecanismos para controlar las informaciones que generan y que son publicadas por los medios; son estos organismos e instituciones quienes tienen un papel activo para poner grandes cantidades de información, que les son beneficiosas, a disposición de los periodistas. 2) Los cambios en la práctica periodística producidos por la incorporación de las nuevas tecnologías han tenido como consecuencia que los periodistas deban pasar más tiempo en las redacciones y dispongan de menos tiempo para salir a la calle en busca de la información.

La mirada de Chomsky y Herman (2001) guarda similitudes con la anterior; pero en su propuesta, para entender el funcionamiento de los medios, hacen más explícitos los mecanismos de poder a través de los cuales los poderosos acceden a los discursos periodísticos y los controlan. El interés de estos autores es revelar cómo el gobierno y los intereses privados dominantes logran que se difundan a la opinión pública los mensajes que les resultan convenientes, mediante el uso de un modelo propagandístico que describen como un conjunto de filtros. Uno de esos filtros es la forma en que se produce el suministro de noticias: la "dependencia de los medios de la información proporcionada por el gobierno, las empresas y los 'expertos', información, por lo demás, financiada y aprobada por esos proveedores principales y por otros agentes del poder" (Chomsky y Herman, 2001: 22). ${ }^{3}$

3 Para los otros filtros esenciales del modelo propagandístico, véase Chomsky y Herman (2001:22). 
Por tanto, un mecanismo fundamental del acceso de los grupos dominantes, esto es, del control de los discursos periodísticos, es a través de la dependencia. Este mecanismo de control es en gran medida de tipo económico. De acuerdo con Chomsky y Herman (2001), frente a la necesidad de los medios de comunicación de masas de flujos constantes y fiables de materia prima informativa -teniendo recursos limitados para lograrla-, las fuentes gubernamentales y empresariales les ofrecen un gran volumen de información que no sólo es gratuita, sino que apenas genera costes de verificación, puesto que es información que se presume fidedigna a diferencia de otras fuentes que no cuentan con esa clase de credibilidad y que generan costes de verificación.

Siguiendo con esta línea argumental, Chomsky y Herman (2001) afirman que las grandes burocracias de los poderosos "subvencionan" a los medios de comunicación, obteniendo a cambio un acceso privilegiado a dichos medios, convirtiéndose en sus fuentes "rutinarias". Pero el poder de estos actores sociales en esta situación no se limitaría a distribuir la información de interés a los medios de comunicación, sino a "vetar" otras informaciones en su contra, pues "resulta muy difícil llamar embusteras a las autoridades de cuyas informaciones depende uno, aunque éstas nos digan grandes mentiras" (Chomsky y Herman, 2001: 57).

En contraposición al periodismo de rutina, Caminos-Marcet (1997) denomina periodismo de investigación a la forma de ejercer la profesión periodística que, entre otras, posee las siguientes características: 1) Busca la verdad oculta. Lo que las personas privadas o instituciones públicas desean mantener oculto y los ciudadanos tienen derecho a conocer. 2) No se apoya en fuentes de información oficiales y recela de ellas; el periodista investigador está más interesado por lo que no dicen u ocultan tales fuentes. Asimismo, es capaz de generar sus propias fuentes de información fuera de los cauces rutinarios. 3) Es un periodismo eminentemente informativo basado en datos absolutamente veraces; por tanto, se apoya en datos comprobados y contrastados a través de diversas fuentes.

Aunque la modalidad del periodismo ejercida está asociada con un cierto producto resultante, no consideramos que el periodismo de rutina sea sinónimo de mala calidad y falto de interés; ni que todo el que adopta la forma de periodismo de investigación sea necesariamente de buena calidad y de interés. Las dos maneras de ejercer la profesión son necesarias y complementarias.

Cabe mencionar que México es un país donde es peligroso ejercer la profesión periodística -en 2016, 11 periodistas y trabajadores en los medios de 
comunicación fueron asesinados (EFE, 2017)-, y el periodismo de investigación es posiblemente el eslabón más débil de la cadena en este sentido. Así, en ciertos aspectos del fenómeno migratorio realizar periodismo de investigación puede suponer un riesgo importante para la integridad física de los periodistas.

En el campo de la migración, Spener (2008) destaca el papel que los medios de comunicación tienen en el establecimiento de un discurso dominante sobre el "contrabando de extranjeros": el gubernamental. Este autor señala que, dada la importancia del discurso de los medios en el conocimiento de la ciudadanía sobre la cuestión, los medios hacen que predominen las visiones de los funcionarios de gobierno y excluyen las perspectivas de otros actores porque: primero, las visiones de los funcionarios son tomadas como dignas de convertirse en noticia por parte de los medios y disponen de infraestructuras de relaciones públicas. Segundo, determinados relatos sobre la labor de los coyotes sólo aparecen en prensa cuando los periodistas tienen tiempo y recursos para realizar reportajes de investigación a fondo. Los hallazgos y señalamientos de Spener están en consonancia tanto con lo enunciado por Caminos-Marcet (1997) como por Chomsky y Herman (2001).

Resultados esperados del análisis de este trabajo de acuerdo con lo anterior:

1. Dada la centralidad en el esquema del periodismo de rutina y el poder económico y de generación de información que poseen habitualmente son poseedores en exclusiva de la información que se deriva de sus actividades respecto a la migración y que recopilan y compilan de diveras maneras-, cabe esperar que los diferentes organismos e instituciones del Estado sean quienes mayor poder tengan sobre y en los discursos periodísticos respecto a la migración centroamericana en tránsito clandestino por México; esto es, los que mayor presencia tengan en los textos periodísticos informativos y los que mayor control tengan respecto a las características del discurso.

2. Que otros actores sociales que formen parte del periodismo de rutina, expertos y miembros de las organizaciones de la sociedad civil (por ejemplo, directores de casas de migrantes, activistas por los derechos humanos) - que guardan cierta o total independencia respecto a los organismos e instituciones del Estado- tengan una presencia significativamente menor, y cuando su voz es recogida en los medios tengan un menor control sobre cómo su discurso es recogido; esto es, menor poder sobre y en el discurso.

3. Que las voces de quienes no formarían parte del periodismo de rutina -los propios migrantes, los “coyotes", la ciudadanía mexicana, entre 
otros- tengan mucho menos poder sobre y en los discursos periodísticos. Así, sus voces quedarán plasmadas en muy pocas ocasiones y exclusivamente a través del periodismo de investigación. Dada su naturaleza de transmigrantes, sería difícil que pudieran convertirse en "activistas" o personalidades y que participaran del periodismo de rutina.

\section{Corpus de noticias y cuestiones metodológicas}

El corpus para el análisis está compuesto de 131 textos informativos publicados en la versión nacional mexicana e impresa de El Universal, ${ }^{4}$ que también están disponibles en la versión online. ${ }^{5}$ En una revisión página por página de las secciones "Nación” y "Estados" en los ejemplares publicados entre enero de 2012 y julio de 2017 -en los meses impares ${ }^{6}$ del año-, se seleccionaron todos los textos de carácter informativo (noticias, reportajes, entrevistas, testimonios y crónicas) referentes a la migración centroamericana en tránsito clandestino por México con destino a Estados Unidos (véase el Cuadro $1^{7}$ ).

Como se puede apreciar en el Cuadro 1, el año 2014 destaca por el mayor número de noticias publicadas (triplican a las recuperadas del año 2016). Esto se debe a que en dicho año se produjo la denominada crisis humanitaria de los "niños, niñas y adolescentes migrantes" (NNAM) en Estados Unidos, que gozó de una gran cobertura mediática. El "problema” no se circunscribía exclusivamente al territorio estadounidense, pues este recalcaba la existencia de un fenómeno de NNAM centroamericanos en tránsito clandestino por

4 De acuerdo con la ACGM (2017a), la tirada de El Universal es de cerca de 120 mil ejemplares de martes a sábado y de 180 mil de domingo a lunes, lo que lo convierte en el diario más leído de México. Los lectores del periódico poseen un estatus socioeconómico que excede ampliamente a la media nacional. Así, mientras que en la población mexicana las personas con doctorado no alcanzan el $1 \%$, la cifra estimada de personas con dicho grado académico entre los lectores de El Universal es del 11\% (ACGM, 2017b).

5 Los textos informativos de la versión impresa de los años analizados se encuentran publicados en la versión online. En ocasiones con ligeras diferencias. Sin embargo, cabe destacar que no todos los textos publicados en la versión online son publicados en la versión impresa. Por tanto, la audiencia potencial de estas noticias es la suma de aquellos que leen la versión impresa y de los que acceden a la digital.

6 Enero, marzo, mayo, julio, septiembre y noviembre. Salvo faltantes puntuales en el acervo de la Hemeroteca Nacional.

7 Todos los cuadros y la gráfica se encuentran en el Anexo, al final del presente artículo (Nota del editor). 
México hacia aquel país -que es parte del fenómeno más amplio de interés en este trabajo (la migración centroamericana en tránsito clandestino por México)-. Es por ello que tanto el hecho de que llegaran a Estados Unidos como el de que transitaran por México "sin ser detectados y detenidos" acapararon un gran interés de los medios de comunicación; incluyendo decenas de portadas y noticias extensas - por ejemplo, a página completa- enfocadas en tal crisis humanitaria, así como varios reportajes de investigación que recuperan las historias de los migrantes centroamericanos -incluyendo NNAM.

En cuanto a la metodología mixta que se aplicó en este trabajo, primero se realizó un análisis cuantitativo utilizando estadística descriptiva que da cuenta de la frecuencia con la que estuvieron presentes en los textos informativos las voces de los diferentes actores sociales, en función del tipo de periodismo - de rutina y de investigación- y la temática de la noticia. Para lo cual nos fijamos en las citas del discurso ajeno, la forma de intertextualidad más evidente según Genette (1989), en estilo directo o indirecto (Reyes, 1995). Asimismo, en esta primera fase se seleccionaron subconjuntos de textos informativos que son similares en cuanto a las tres categorías de análisis (actor social destacado en la noticia, práctica del periodismo y temática).

En la segunda fase se hace una descripción cualitativa de los textos seleccionados, lo cual permite una mayor comprensión sobre la manera en que los discursos de los distintos actores sociales son referidos en los textos y forman parte de los discursos periodísticos; teniendo en cuenta que en última instancia los discursos periodísticos están en manos de los periodistas. Además, tanto la fase cuantitativa como la cualitativa nos permiten hacer inferencias respecto al poder que los actores sociales tienen sobre y en el discurso periodístico.

Tras una revisión preliminar de los textos informativos, se consideró que los actores sociales, cuyas voces quedan reflejadas en aquellos, pueden clasificarse en función del rol que desempeñan en el fenómeno de la migración en tránsito (véase Cuadro 2). Cabe señalar que el análisis se llevó a cabo teniendo en cuenta al actor social, cuya voz destaca en cada uno de los textos informativos seleccionados (la que es referida en el titular, aparece en primer lugar en el texto y/o se le otorga mayor espacio en el mismo).

Para clasificar las noticias de acuerdo con las modalidades de periodismo que presumiblemente las generaron -rutina o investigación-, se pueden observar ciertas características presentes en los textos periodísticos informativos (véase Cuadro 3).

La clasificación de temas se realizó teniendo en cuenta el tema principal del texto informativo (véase cuadro 4); que, por lo general, es el tema que 
aparece en primer lugar y de mayor relevancia, el que cubre gran parte del contenido del texto y que frecuentemente está resumido en el titular. Como señala van Dijk (1990), una característica relevante del discurso periodístico es que sus temas se pueden plasmar y señalar mediante titulares. Por supuesto, varios de los textos informativos aluden a la vez a más de una de las temáticas.

\section{La intertextualidad en los textos periodísticos sobre la transmigración centroamericana clandestina}

\section{Fase cuantitativa}

La Gráfica 1 muestra que la mayoría de los textos informativos refieren a por lo menos una voz de los actores sociales (sólo el 2.3\% no recupera ninguna). En dicha gráfica se destaca el hecho de que los actores estatales nacionales constituyen la referencia principal: más del $40 \%$ de las veces. En segundo y tercer lugar le siguen las voces de los defensores de los migrantes y de los propios migrantes, que son referidas en el 26.7 y $13 \%$ de los textos, respectivamente. Las voces de la academia y de los "coyotes" tienen escasa presencia: menos de $4 \%$ de los textos cada una de ellas. Asimismo, cabe resaltar que las voces de los ciudadanos mexicanos brillan por su ausencia en los textos informativos respecto a la migración centroamericana en tránsito clandestino por México.

El Cuadro 5 nos permite indagar sobre la manera en que las diferentes voces de los actores sociales son referidas en función del tipo de periodismo. En primer lugar, cabe mencionar que aproximadamente uno de cada cinco textos informativos sobre la migración centroamericana en tránsito clandestino por México corresponde al periodismo de investigación. Esta cifra, nada desdeñable, es en gran medida resultado de la prominencia que el fenómeno de la migración en tránsito alcanzó en determinados momentos (véase, la crisis humanitaria de los NNAM en 2014), lo cual supuso que se dedicaran más recursos a hacer investigaciones de esta clase.

Como se aprecia en el Cuadro 5, los diferentes actores sociales tienden a aparecer en mucha mayor proporción en noticias generadas por el periodismo de investigación frente al periodismo de rutina, o viceversa. Así, las voces de: academia, actores estatales nacionales y extranjeros, y defensores son recogidas como actores destacados en los textos generados por el periodismo de rutina. Por el contrario, las voces de los migrantes en tránsito y los "coyotes" son referidos mayoritariamente como actores destacados por el periodismo de investigación. 
De acuerdo con lo anterior, los actores estatales nacionales son los que más poder tendrían sobre los discursos, pues son los que mayor presencia tienen en los textos informativos generados por el periodismo de rutina, aquel que deja la iniciativa a las fuentes oficiales de información. Segundo, en esta misma práctica del periodismo, los defensores de los migrantes están referidos de manera destacada; serían los actores con más poder en segundo lugar. Tercero, a pesar de estar presentes en más de un $10 \%$ de los textos, el poder de los migrantes sobre el discurso se ve matizado en el hecho de que aparecen en textos generados por el periodismo de investigación, en el cual son los periodistas quienes tienen un rol más activo y menos neutro (interpretativo) en la construcción del discurso.

Como se observa en el Cuadro 6, los diferentes actores sociales tienen una presencia heterogénea según la temática. Los actores estatales aparecen principalmente en los textos informativos sobre "política migratoria" e implementación que ellos realizan. Los actores estatales extranjeros también aparecen referidos en primer lugar en los textos sobre "política migratoria". Por su parte, la presencia en los textos de los defensores de los migrantes está dividida en los temas sobre "política migratoria" y "delincuencia y victimización”. En cuanto a los migrantes en tránsito, estos son referidos en los textos informativos sobre "migrantes y el tránsito" -los escritos que cuentan las historias de los migrantes tienen necesariamente que recuperar las voces de los propios migrantes-.

A continuación se analizan cualitativamente los tres tipos de textos informativos más frecuentes, que son generados por el periodismo de rutina y se refieren a: 1) los actores estatales en la temática "política migratoria"; 2) los defensores de los migrantes en las temáticas: "política” y "delincuencia y victimización”; y que son generados por el periodismo de investigación y se refieren a 3) los propios migrantes en tránsito en la temática de "migrantes y tránsito".

\section{Fase cualitativa}

Voces de los actores estatales nacionales reflejadas por el periodismo de rutina en la temática "política migratoria"

En este apartado, los aspectos para tener en cuenta son tres:

Primero. La política migratoria. Las voces de los actores estatales nacionales son fundamentales para entender la política migratoria, ya que son quienes la definen a través de leyes, reglamentos y políticas, y anuncian los cambios que producirán en ella. 
Así, algunos titulares señalan: "Publican reglamento de Ley de Migración” (Morales, 2012), "Afirma INM que depurará sus filas" (Otero, 2013), "Crearán coordinación para atender flujo migratorio en la frontera sur" (García, 2014); “México alista plan para niños migrantes” (Gómez-Quintero, 2015), entre otras.

Segundo. La implementación. Frecuentemente, los textos informativos recogen la voz de los actores estatales nacionales: 1) describiendo la manera en que ellos mismos están implementando la política migratoria en casos particulares, y 2) sus anuncios y "promesas" respecto a cómo será la implementación en el futuro.

1) Los actores estatales nacionales aparecen en textos informativos que reflejan determinadas actuaciones de implementación de la política migratoria, conducidas por autoridades migratorias y otros actores estatales. Dichos textos recuperan explícita o implícitamente las voces de los actores estatales nacionales plasmadas en comunicados de prensa -transcripciones más o menos fieles de estos últimos-. Esos textos están sesgados en al menos dos sentidos: primero, sólo se recuperan las actuaciones que a los actores estales nacionales les conviene mostrar, para "probar" que están cumpliendo eficazmente los mandatos legales; y, segundo, están redactados de una manera que favorece la valoración positiva de las mismas y minimiza las posibilidades de rechazo por parte de los lectores.

Así, estos textos informativos destacan los "rescates" de los migrantes y su protección por parte de las autoridades estatales nacionales; por tanto, se reafirma el cumplimento de la faceta garantista de derechos de los migrantes de la política migratoria mexicana que ha sido plasmada legalmente en la Ley de Migración de 2011 y su reglamento de 2012. Por ejemplo, una noticia titulada: "Rescata INM a 147 migrantes abandonados en Veracruz" señala en su párrafo de arranque o lead:

El Instituto Nacional de Migración (INM) rescató a 147 migrantes originarios de Honduras, Guatemala, El Salvador y Nicaragua que fueron abandonados sin agua ni alimento por presuntos traficantes de personas, en una zona cercana al tramo Los Naranjos, en el municipio de Ozuluama, Veracruz (Morales, 2017).

Además de destacar una actuación del INM, la noticia está redactada de un modo que genera una imagen positiva del proceder de tal institución, al definir la actuación como -rescate-, y al incluir aspectos concretos del acontecimiento que dan una imagen muy positiva del actuar del INM en pro de la protección de los migrantes:

Personal del Instituto brindó atención médica y les proporcionó agua y alimento al grupo conformado por 48 menores de edad ( 14 de ellos no acompañados) y 99 
adultos, quienes eran originarios de Honduras, Guatemala, El Salvador y Nicaragua (Morales, 2017).

Cuando los textos informativos de este tipo refieren a las actuaciones de detención y deportación de migrantes, es decir, a la faceta de la implementación de la política de control migratorio, la redacción recurre frecuentemente a eufemismos para "hacer irreprochables" las actuaciones de las autoridades migratorias y tienden a enfatizar que se estaría cumpliendo con la faceta garantista de la política migratoria consagrada legalmente.

Por tanto, cabe preguntarse hasta qué punto los textos informativos de esta clase recogen acontecimientos que son realmente de interés periodístico; o por el contrario, son textos al servicio de la propaganda gubernamental. En cualquier caso, parece inadecuada la manera poco crítica en que se transcriben los comunicados de prensa, en una lógica de periodismo de rutina. Dada la presunción de objetividad de los textos informativos, los medios de comunicación deben tener especial cuidado en definir lo que merece ser noticia y lo que no amerita tal tratamiento.

2) Las promesas de los actores estatales nacionales respecto a la futura implementación de la política también forman parte de los textos informativos:

México prometió a Centroamérica que dará un tratamiento digno y de profundo respeto a los derechos humanos de los migrantes irregulares de esa región que transitan por el territorio mexicano rumbo a Estados Unidos (Meléndez, 2014).

Como se puede apreciar, estas promesas pueden recalcar la faceta garantista de derechos de la política migratoria, evitando aludir a la faceta de seguridad y control que la misma posee, y que en buena medida son respuesta a las peticiones de otros actores sociales -los defensores de los migrantes y los actores estatales extranjeros-.

Tercero. El deber ser de la política migratoria y de su implementación. Las voces estatales nacionales aparecen referidas en los textos informativos en cuanto al deber ser de la política migratoria y el de su implementación. Algunas voces cuestionan las actuaciones del gobierno desde una posición como actores estatales nacionales.

Con base en los párrafos anteriores, cabe concluir que los textos informativos no siempre recogen las voces de los actores estatales de un modo adecuado, al reproducir sus declaraciones y comunicados de prensa de manera poco crítica, dando lugar a textos que en el mejor de los casos son irrelevantes y anodinos, y en el peor podrían considerarse de contenido propagandístico. Un ejemplo de hasta qué extremo los textos incurren en un periodismo de poca calidad son las reproducciones de frases tipo eslogan: "El organismo [el INM] aclaró que 'con estas acciones se ratifica el compromiso de proteger la 
integridad física y los derechos humanos de los migrantes, independientemente de su nacionalidad y condición migratoria"' (Notimex, 2013).

Las voces de los defensores de los migrantes reflejadas en el periodismo de rutina en las temáticas "política migratoria” y "delincuencia y victimización"

Los textos informativos analizados traen a colación las declaraciones críticas, de los que hemos denominado defensores de los migrantes -curas, activistas, entre otros-, respecto a la política migratoria mexicana y su implementación, denunciando determinadas situaciones y reclamando mejoras en el trato hacia los migrantes centroamericanos en tránsito por México. Así, en medio de la crisis humanitaria de los NNAM se dieron varias noticias, como las siguientes, por parte de:

- Organismos internacionales. "ONU urge a garantizar derechos de migrantes" (Notimex, 2014), cuyo lead señala: "la Organización de las Naciones Unidas (ONU), cuya secretaría general encabeza Ban Ki-moon, urgió ayer a los países de origen, tránsito y destino a que respeten los derechos de los migrantes, en especial cuando se trata de menores que viajan sin la compañía de un adulto" (Notimex, 2014).

- La Iglesia católica. "Migración legal y segura, reclaman" (Gómez y Reséndiz, 2014). En su cuerpo se retoman declaraciones del papa Francisco leídas por el secretario de Estado del Vaticano, Pietro Parolin: "Es necesario que todos cambiemos la perspectiva hacia los emigrantes, que pasemos de una perspectiva de defensiva y miedo, desinterés y marginación, que en el fondo corresponden a la cultura del descarte, a una perspectiva basada en la cultura del encuentro" (Gómez y Reséndiz, 2014).

- Organizaciones no gubernamentales. "Denuncian redadas en tren 'El Diablo”" (Sánchez, 2014). En el segundo párrafo del texto informativo se señala que "la Coalición Pro Defensa del Migrante denunció la detención de los migrantes en la vía pública, cuando bajaban del tren, cuyo argumento para actuar en contra de los indocumentados es que recibieron 'denuncias de particulares por supuestas anomalías”” (Sánchez, 2014).

Estrechamente ligado con lo anterior, las voces de los defensores están reflejadas en textos informativos que denuncian acciones criminales de las que los migrantes son víctimas. Los acontecimientos no se convierten en noticia de manera directa, sino a través de las denuncias que los defensores de los migrante realizan.

Una noticia cuyo titular indica "Denuncian nuevos plagios de migrantes” (Barboza, 2013) señala en sus dos primeros párrafos: 
Nuevos secuestros de migrantes centroamericanos viajan en el tren carguero de la ruta Tenosique-Coatzacoalcos, controlada por el crimen organizado, fueron perpetrados del 14 al 17 de mayo, sin que las autoridades hagan algo por impedirlo.

Así lo informó Fray Tomás González del Castillo, director del Hogar Refugio para Personas Migrantes La 72, del municipio de Tenosique, quien precisó que el suceso se dio a conocer públicamente hasta este domingo, por seguridad de las víctimas que fueron plagiadas y por las que se pagó hasta 3 mil dólares de rescate (Barboza, 2013).

La voz de los defensores en ambas materias "política migratoria” y "delincuencia y victimización" se aborda en textos informativos que convierten las declaraciones e informes de estos actores sociales en noticia, cuya reputación y credibilidad hace que sea "innecesario" la contrastación de tal información, según la práctica del periodismo de rutina. En estos textos, la voz de los defensores de los migrantes se alza en pro de aquellos que no tiene voz, los migrantes, o al menos de quienes no tienen la capacidad de acceso a los medios que estos actores sociales poseen.

Las voces de los migrantes reflejadas en el periodismo de investigación en la temática de "migrantes y el tránsito"

Las voces de los migrantes se hacen presentes en reportajes de investigación donde los periodistas reflejan la realidad de la migración centroamericana en tránsito clandestino, a través de las historias de los migrantes y sus experiencias en tránsito. Aunque en estos reportajes aparecen voces de distintos actores sociales, según la máxima del periodismo de investigación de recuperar lo que dicen los diferentes implicados, son los migrantes y sus relatos los que adquieren mayor protagonismo.

En "Migrantes, en la ruta del infierno" (Cha'ca y Quadratín, 2015) se relata la historia de seis migrantes centroamericanos que se dirigen a Estados Unidos y pasan por entre Chiapas y Oaxaca, enfrentando diversos peligros: "los uniformados" (agentes del INM) y los asaltantes. Los seis protagonistas pronto caen en manos de un asaltante armado con una escopeta, quien los obliga a desnudase y les roba todas sus pertenencias. Ya sin mochilas ni dinero acaban la jornada en un albergue. La noticia incorpora informaciones e informes de defensores de los migrantes sobre zonas peligrosas para quienes migran y sobre el incremento de la criminalidad y de la vulnerabilidad de estos.

En “"El diablo', nuevo tren de migrantes” (Sánchez, 2013) se narra la historia de una pareja de migrantes guatemaltecos en su tránsito por México por la denominada ruta del Pacífico. Durante su trayecto tuvieron que lidiar 
con diversos grupos criminales y presuntos agentes estatales, así como con las altas temperaturas al viajar sobre los techos de varios trenes. La noticia incorpora información de defensores de los migrantes religiosos y no religiosos, funcionarios y organismos internacionales para referirse a las rutas por donde transitan los migrantes por México y agentes del estado.

Dado que el periodista es la parte activa de la investigación, las declaraciones de los migrantes captadas mediante entrevistas y plasmadas en los textos informativos son espontáneas y poco elaboradas, pues fueron recabadas y moldeadas según los intereses discursivos del periodista.

Estos reportajes de investigación muestran -como se puede apreciar en los dos ejemplos expuestos- a los migrantes como sujetos en busca de una vida mejor, y señalan, de manera crítica, cómo son perseguidos por las autoridades migratorias mexicanas y cómo son víctimas de la delincuencia. Se trata de textos informativos donde los periodistas abogan por los migrantes desarrollando discursos similares a los defensores de estos últimos y que permiten sensibilizar a la población en general sobre los padecimientos de los migrantes en tránsito por México, a través de hacer públicas sus experiencias.

El análisis cualitativo realizado nos permite complementar las inferencias en cuanto al poder, dando cuenta de la manera en que el periodismo de rutina y el de investigación suponen tratamientos muy diferentes de las voces de los actores sociales. En este sentido, el poder en cuanto a los discursos periodísticos de El Universal-respecto a la migración centroamericana en tránsito clandestino- que tienen los actores estatales nacionales es mayor que el de otros actores sociales, por la combinación de una mayor frecuencia de su presencia en el periodismo de rutina y de su capacidad para sacar provecho del funcionamiento del mismo para influir en las características de los textos informativos: temas que se van a tratar, lenguaje utilizado, aspectos por abordar en las noticias, etc.; en otras palabras, muestran un gran poder sobre y en el discurso periodístico.

Pero este poder de los actores estatales nacionales no es omnímodo en la medida en que -como se aprecia en los textos informativos analizadoslos defensores de los migrantes también forman parte de ese periodismo de rutina, con una cuota importante de poder sobre el discurso periodístico. Asimismo, en los textos informativos de El Universal quedan plasmados los discursos contrahegemónicos de tales actores sociales que se oponen a los discursos de los actores estatales nacionales; por tanto, también ostentan un considerable poder en el discurso.

Las voces de los migrantes en tránsito por México aparecen con relativa frecuencia en los textos informativos de El Universal sobre la migración 
centroamericana en tránsito clandestino por México. Sin embargo, esto no se corresponde con una "cuota" equivalente de poder sobre y en los discursos periodísticos en torno al fenómeno migratorio que ellos protagonizan. Esto se debe a que su presencia responde a los intereses informativos y a la iniciativa de los periodistas, y no a la de los propios migrantes, por más que sean textos con discursos que pretenden el beneficio de estos últimos, ya que los periodistas enarbolan discursos similares a los de los defensores de los migrantes.

Otros actores sociales tienen una menor presencia en los textos informativos. Así las voces de los "actores estatales extranjeros" forman parte del periodismo de rutina, pero su importancia sería mucho menor que la de los "actores estatales nacionales". Las voces de los "coyotes" tienen muy escasa presencia y es referida por el periodismo de investigación. En ambos casos con las implicaciones que vimos tiene el tipo de periodismo practicado sobre la manera en que se da paso los discursos de otros actores sociales. La gran ausente es la ciudadanía, cuyos discursos, actitudes y opiniones no aparecen reflejadas en el corpus analizado.

\section{Conclusiones}

Los textos informativos sobre migración centroamericana en tránsito clandestino por México de El Universal recuperan en gran medida las voces de diversos actores sociales; esto es, los discursos periodísticos están compuestos, en su mayoría, por fragmentos de los discursos de otros actores sociales. Sin embargo, no todos los actores están referidos con la misma frecuencia y de la misma forma.

Como se esperaba, los actores estatales fueron referidos en mayor número de ocasiones y de un modo por el periodismo de rutina que permite inferir que son los que más poder ostentaron sobre y en los discursos periodísticos respecto a la migración centroamericana en tránsito clandestino por México. En segundo lugar, estarían los defensores de los migrantes que también gozarían de un gran acceso a los discursos por parte del periodismo de rutina. Si damos cuenta del contenido de los discursos de ambas clases de actores, se puede observar que en gran medida se trata de discursos antagónicos, por lo que El Universal estaría brindando elementos en sus páginas noticiosas para alimentar el necesario debate social respecto al fenómeno.

Las voces de los propios migrantes tienen cabida en las páginas del periódico a través de la mirada del periodismo de investigación. Su menor presencia y la manera en que son recogidas sus voces indican el escaso poder sobre 
y en el discurso. Sin embargo, su presencia fue mayor de la esperada y es relevante en términos de sensibilización de la población con la "problemática" de la migración centroamericana en tránsito clandestino por México.

Los resultados obtenidos muestran que los textos informativos analizados corresponden más al esquema del periodismo de rutina postulado por Caminos-Marcet (1997), que a un esquema de propaganda política como el formulado por Chomsky y Herman (2001). Primero, aunque hay un predominio del periodismo de rutina y de las fuentes informativas que forman parte de esta manera de hacer periodismo, no todas podrían considerarse "fuentes de rutina”, en el sentido de Chomsky y Herman (2001), como queda patente cuando se da cabida a los defensores de los migrantes. Segundo, El Universal otorga un espacio muy significativo a los discursos críticos con las actuaciones del gobierno enarbolados por defensores de los migrantes y otros actores; voces manifiestamente antagónicas con los discursos de los actores estatales nacionales respecto a la política migratoria mexicana y su implementación en cuanto al fenómeno de la migración en tránsito clandestino por México.

Aunque hay un predominio del periodismo de rutina en el tema que nos ocupa, El Universal hace gala de un interés por complementarlo con textos informativos generados como resultado del periodismo de investigación -donde suele abogar por la defensa de los migrantes-. En cualquier caso, parece encomiable que dicho periódico incremente la práctica del periodismo de investigación en general y ponga un mayor énfasis en los actores estatales nacionales en particular. Asimismo, que tome un rol más activo y crítico en cuanto a cómo recoge los discursos de los actores sociales en el periodismo de rutina; esto es, filtrar de manera más fina lo que no constituye hechos noticiosos, procurar que la redacción sea clara y propia de los textos periodísticos, entre otras posibles mejoras.

Futuras investigaciones podrán indagar y analizar de forma más directa y en mayor profundidad las relaciones de poder establecidas entre los diferentes actores sociales y periodistas que cubren la materia migratoria, las cuales tiene gran relevancia en la determinación del contenido de los discursos periodísticos; además de examinar los mecanismos de poder que las generan. Respecto a tales relaciones, en este trabajo sólo hemos podido realizar algunas limitadas inferencias.

También queda pendiente para futuras investigaciones analizar con mayor detalle el contenido sustantivo de los discursos periodísticos de la prensa mexicana, teniendo en cuenta que reflejan los discursos de otros actores sociales y que son clave en cómo la ciudadanía mexicana entiende las cuestiones referentes a la migración. 
Eduardo Torre-Cantalapiedra. Periodismo, actores sociales y migración: intertextualidad en los discursos periodisticos sobre migración

\section{Referencias}

ACGM (2017a), El Universal. El gran diario de México. Circulación y Cobertura. Disponible en: http://pnmi.segob.gob.mx/PNMP_resultadosmi.php?idr=611\&medio=3 [20 de noviembre de 2017].

ACGM (2017b), El Universal. El gran diario de México. Perfil de lector. Disponible en: http://pnmi.segob.gob.mx/PNMP_resultadosmi.php?idr=611\&medio=3 $\left[\begin{array}{ll}20 & \mathrm{de}\end{array}\right.$ noviembre de 2017].

Alonso, Luís Enrique y Callejo, Javier (1999), "El análisis del discurso: del postmodernismo a las razones prácticas”, en Revista Española de Investigaciones Sociológicas: REIS, núm. 88, España: Centro de Investigaciones Sociológicas. Disponible en: https://www.jstor. org/stable/40184203?seq=1\#page_scan_tab_contents [20 de noviembre de 2017].

Barboza, Roberto (2013), "Denuncian nuevos plagios de migrantes", en El Universal, 20 de mayo, México.

Bruno, Sebastián (2010), “Cifras imaginarias de la inmigración limítrofe en la Argentina” en Novick, S. [dir.], Migraciones y Mercosur: una relación inconclusa, Argentina: Catálogos. Disponible en: http://webiigg.sociales.uba.ar/pobmigra/archivos/migraymercosur. pdf [20 de noviembre de 2017].

Caminos-Marcet, José María (1997), Periodismo de investigación. Teoría y práctica, España: Síntesis.

Casero-Ripollés, Andreu (2007), "Discurso mediático, inmigración e ilegalidad: legitimar la exclusión a través de la noticia”, en Zapata-Barrero, R. y van Dijk, T. [eds.], Discursos sobre la inmigración en España. Los medios de comunicación, los parlamentos y las administraciones, España: Fundación CIDOB.

Cha'ca, Roselia y Quadratín (2015), “Migrantes en la ruta del infierno”, en El Universal, 29 de enero, México.

Chomsky, Noah y Herman, Edward (2001), Los guardianes de la libertad: propaganda, desinformación y consenso en los medios de comunicación de masas, España: Crítica.

De la Fuente-García, Mario (2017), "Análisis crítico del discurso y racismo en los medios de comunicación”. Disponible en: http://www.mariodelafuente.org/documentos/ analisis-critico-del-discurso-y-racismo-en-los-medios-de-comunicacion.pdf $[20$ de noviembre de 2017].

EFE (2017), “México, tercer país más peligroso para la prensa, alertan”, en El Universal, 3 de febrero, México.

Fairclough, Norman (1995), Critical Discourse Analysis: The Critical Study of Language, USA: Longman.

García, Ariadna (2014), "Crearán coordinación para atender flujo migratorio en la frontera sur”, en El Universal, 9 de julio, México.

Genette, Gérard (1989), Palimpsestos. La literatura en segundo grado, España: Taurus.

Gómez-Quintero, Natalia (2015), “México alista plan para niños migrantes”, en El Universal, 7 de enero, México.

Gómez, Natalia y Reséndiz, Francisco (2014), “Migración legal y segura, reclaman”, en El Universal, 15 de julio, México.

Grijelmo, Álex (2014), El estilo del periodista, México: Taurus.

Kristeva, Julia (1997), "Bajtín, la palabra, el diálogo y la novela”, en Desiderio, N. [comp.], Intertextuallté, Cuba: UNEAC, Casa de las Américas. 
Meléndez, José (2014), “SRE promete trato digno a migrantes de Centroamérica”, en El Universal, 4 de julio, México.

Méndez-García de Paredes, Elena (2000), "La literalidad de la cita en los textos periodísticos", en Revista Española de Lingüistica, vol. 30, núm. 1, España: Sociedad Española de Lingüística.

Morales, Alberto (2012), “Publican reglamento de Ley de Migración”, en El Universal, 28 de septiembre, México.

Morales, Alberto (2017), “Rescata INM a 147 migrantes abandonados en Veracruz”, en El Universal, 30 de julio, México.

Nash, Mary (2005), Inmigrantes en nuestro espejo: inmigración y discurso periodistico en la prensa española, España: Icaria.

Notimex (2013), "Refuerzan protección a migrantes”, en El Universal, 29 de noviembre, México.

Notimex (2014), "ONU urge garantizar derechos de migrantes”, en El Universal, 4 de julio, México.

Otero, Silvia (2013), “Afirma INM que depurará sus filas”, en El Universal, 26 de septiembre, México.

Retis, Jessica (2004), "La imagen del otro: inmigrantes latinoamericanos en la prensa nacional española”, en Sphera Pública: Revista de Ciencias Sociales y de la Comunicación, núm. 4, España: Universidad Católica San Antonio de Murcia.

Reyes, Graciela (1995), Los procedimientos de la cita: estilo directo y estilo indirecto, España: Arcos Libros.

Rodrigo-Alsina, Miquel (1989), La construcción de la noticia, Barcelona: Paidós.

Ruiz-Ruiz, Jorge (2009), "Análisis sociológico del discurso: métodos y lógicas", en Forum: Qualitative Social Research, vol. 10, núm. 2, Alemania: Freie Universität Berlin.

Sánchez, Laura (2013), “El diablo', nuevo tren de migrantes”, en El Universal, 14 de julio, México.

Sánchez, Laura (2014), "Denuncian redadas en tren 'El Diablo”, en El Universal, 13 de julio, México.

Spener, David (2008), "El Apartheid global, el coyotaje y el discurso de la migración clandestina: distinciones entre violencia entre violencia personal, estructural y cultural", en Migración y Desarrollo, núm. 10, México: Red Internacional de Migración y Desarrollo.

van Dijk, Teun (1990), La noticia como discurso. Comprensión, estructura y producción de la información, España: Paidós.

van Dijk, Teun (1999), "Análisis crítico del discurso", en Revista Anthropos: Huellas del conocimiento, núm. 186, España: Proyecto A Ediciones. 
Anexo

\section{Cuadro 1}

Volumen de noticias referentes a la migración centroamericana en tránsito clandestino por México por año, 2012-2017*

\begin{tabular}{cccccccc}
\hline & 2012 & 2013 & 2014 & 2015 & 2016 & 2017 & Total \\
\hline Número de textos & 20 & 25 & 45 & 18 & 15 & 8 & 131 \\
\hline
\end{tabular}

Fuente: Elaboración propia con base en los textos seleccionados de "El Universal".

${ }^{*}$ Se revisaron exclusivamente los ejemplares de periódico correspondientes a los meses impares. El año 2017 sólo incluye hasta el mes de julio.

\section{Cuadro 2}

Actores sociales referidos en los textos informativos sobre migración centroamericana en tránsito clandestino

\begin{tabular}{ll}
\hline \multicolumn{1}{c}{ Actores } & \multicolumn{1}{c}{ Descripciones } \\
\hline Academia & Investigadores y expertos en el fenómeno de la migración en tránsito. \\
\hline $\begin{array}{l}\text { Actores estatales } \\
\text { nacionales }\end{array}$ & $\begin{array}{l}\text { Funcionarios y agentes de las diferentes instituciones del Estado } \\
\text { mexicano: Instituto Nacional de Migración (INM), Secretaría de } \\
\text { Gobernación, cancillería, diputados, senadores, entre otros. }\end{array}$ \\
\hline $\begin{array}{l}\text { Actores estatales } \\
\text { extranjeros }\end{array}$ & $\begin{array}{l}\text { Funcionarios y agentes de las diferentes instituciones de los Estados } \\
\text { de Centroamérica y Estados Unidos (embajadores, presidentes, } \\
\text { autoridades migratorias, entre otros). }\end{array}$ \\
\hline Coyotes & $\begin{array}{l}\text { Quienes transportan a los migrantes a través de las fronteras } \\
\text { internacionales y el territorio mexicano a cambio de una cierta suma de } \\
\text { dinero. }\end{array}$ \\
\hline Defensores & $\begin{array}{l}\text { Defensores de los migrantes: religiosos, organizaciones de la sociedad } \\
\text { civil, organismos internacionales, Comisión Nacional de Derechos }\end{array}$ \\
\hline Humanos.
\end{tabular}

Fuente: Elaboración propia. 


\section{Cuadro 3}

\section{Caracterísiticas de los textos informativos en función de la práctica del periodismo}

\begin{tabular}{|c|c|c|}
\hline Característica & Periodismo de rutina & Periodismo de investigación \\
\hline $\begin{array}{l}\text { Fuentes de } \\
\text { información } \\
\text { principal }\end{array}$ & $\begin{array}{l}\text { Primacía de fuentes oficiales. Las } \\
\text { fuentes de otros actores sociales, } \\
\text { de aparecer, son habitualmente } \\
\text { filtradas por la propia fuente } \\
\text { oficial. }\end{array}$ & $\begin{array}{l}\text { Fuentes no oficiales. Habitualmente } \\
\text { diversidad fuentes de información. } \\
\text { Polifonía de voces. }\end{array}$ \\
\hline $\begin{array}{l}\text { Lenguaje } \\
\text { propio o } \\
\text { ajeno }\end{array}$ & $\begin{array}{l}\text { El lenguaje utilizado contiene } \\
\text { más elementos ajenos a la práctica } \\
\text { periodística; destaca el uso de } \\
\text { léxico ajeno: tecnicismos y } \\
\text { eufemismos. }\end{array}$ & $\begin{array}{l}\text { El lenguaje informativo tiene un } \\
\text { estilo propio que tiene como una de } \\
\text { sus más importantes características } \\
\text { la claridad (Martínez Albertos, } \\
\text { 1974). }\end{array}$ \\
\hline $\begin{array}{l}\text { Trabajo de } \\
\text { campo }\end{array}$ & $\begin{array}{l}\text { Abundan transcripciones de } \\
\text { notas de prensa de entes oficiales } \\
\text { o se cubren ruedas de prensa, } \\
\text { pero no suponen la realización de } \\
\text { una verdadera labor de campo. }\end{array}$ & $\begin{array}{l}\text { Por lo general, denotan la } \\
\text { realización de investigación en } \\
\text { campo. Por ejemplo, presentan } \\
\text { fragmentos de entrevistas efectuadas } \\
\text { por el periodista. }\end{array}$ \\
\hline $\begin{array}{l}\text { Contraste } \\
\text { de la } \\
\text { información }\end{array}$ & $\begin{array}{l}\text { No queda patente que se haya } \\
\text { realizado contrastación de la } \\
\text { información. }\end{array}$ & $\begin{array}{l}\text { Pueden expresar directamente que } \\
\text { se hizo una comprobación de la } \\
\text { información. }\end{array}$ \\
\hline $\begin{array}{l}\text { Tipo de texto } \\
\text { informativo y } \\
\text { extensión }\end{array}$ & $\begin{array}{l}\text { Suelen ser noticias, con } \\
\text { frecuencia de corta extensión o } \\
\text { intermedia. }\end{array}$ & $\begin{array}{l}\text { Abundan las noticias extensas, } \\
\text { crónicas y reportajes. }\end{array}$ \\
\hline
\end{tabular}

Fuente: Elaboración propia. 
Eduardo Torre-Cantalapiedra. Periodismo, actores sociales y migración: intertextualidad en los discursos periodisticos sobre migración

\section{Cuadro 4}

Tipología de textos informativos sobre migración centroamericana en tránsito clandestino según los diferentes temas abordados

\begin{tabular}{ll}
\hline \multicolumn{1}{c}{ Temáticas } & \multicolumn{1}{c}{ Descripciones } \\
\hline Coyotaje & Enfocados en la actividad de los “coyotes” y "polleros”. \\
\hline $\begin{array}{l}\text { Delincuencia } \\
\text { y } \\
\text { víctimización }\end{array}$ & $\begin{array}{l}\text { Relatan los diferentes tipos de delincuencia y violencia en contra } \\
\text { de los migrantes por parte de distintos actores sociales (criminales, } \\
\text { autoridades corruptas) y/o muestran a los migrantes como víctimas o } \\
\text { potenciales víctimas de tales delitos. }\end{array}$ \\
\hline $\begin{array}{l}\text { Magnitud de } \\
\text { flujos }\end{array}$ & $\begin{array}{l}\text { Refieren a las cifras de los flujos de migrantes en tránsito y deportados } \\
\text {-referidos a la población centroamericana- y los cambios en que en estas } \\
\text { se producen. }\end{array}$ \\
\hline $\begin{array}{l}\text { Migrantes y el } \\
\text { tránsito }\end{array}$ & $\begin{array}{l}\text { Recuperan los relatos de los propios migrantes en su tránsito por } \\
\text { México y sobre las vicisitudes que encuentran en el camino. }\end{array}$ \\
\hline $\begin{array}{l}\text { Política } \\
\text { migratoria }\end{array}$ & $\begin{array}{l}\text { Respecto a la política migratoria mexicanas referida a la migración } \\
\text { centroamericana en tránsito y los migrantes en tránsito y su } \\
\text { implementación. }\end{array}$ \\
\hline Otras & Otras temáticas: casas del migrante. \\
\hline
\end{tabular}

Fuente: Elaboración propia. 


\section{Cuadro 5}

Frecuencia de la presencia de voces de los actores sociales* en los textos sobre la migración centroamericana en tránsito clandestino por México según el tipo de periodismo, 2012-2017 ${ }^{* *}$

\begin{tabular}{lccc}
\hline & Rutina & Investigación & Total \\
\hline Academia & 5 & 0 & 5 \\
\hline Actores estatales nacionales & 52 & 2 & 54 \\
\hline Actores estatales extranjeros & 12 & 1 & 13 \\
\hline Coyotes & 0 & 4 & 4 \\
\hline Defensores & 29 & 6 & 35 \\
\hline Transmigrantes & 4 & 13 & 17 \\
\hline Ninguna & 2 & 1 & 3 \\
\hline Total & 104 & 27 & 131 \\
\hline$\%$ & 79.4 & 20.6 & 100.0 \\
\hline
\end{tabular}

Fuente: Elaboración propia con base en los textos seleccionados de "El Universal".

* En el caso de que la noticia refiera la voz de dos o más actores sociales, sólo se tiene en cuenta el de más relevancia.

** Se revisaron exclusivamente los ejemplares de periódico correspondientes a los meses impares. El año 2017 sólo incluye hasta el mes de julio. 
Eduardo Torre-Cantalapiedra. Periodismo, actores sociales y migración: intertextualidad en los discursos periodísticos sobre migración

\section{Cuadro 6}

Frecuencia de la presencia de voces de los actores sociales* en los textos sobre la migración centroamericana en tránsito clandestino por México según temáticas abordadas, 2012-2017**

\begin{tabular}{lcccccc}
\hline & Coyotaje & $\begin{array}{c}\text { Delincuenciay } \\
\text { victimización }\end{array}$ & $\begin{array}{c}\text { Magnitud } \\
\text { de las cifras }\end{array}$ & $\begin{array}{c}\text { Migrantes y } \\
\text { el tránsito }\end{array}$ & $\begin{array}{c}\text { Política } \\
\text { migratoria }\end{array}$ & Otros \\
\hline Academia & 0 & 1 & 1 & 0 & 2 & 1 \\
\hline $\begin{array}{l}\text { Actores est. } \\
\text { nacionales }\end{array}$ & 1 & 6 & 7 & 3 & 35 & 2 \\
\hline $\begin{array}{l}\text { Actores est. } \\
\text { extranjeros }\end{array}$ & 1 & 1 & 3 & 0 & 7 & 1 \\
\hline Coyotes & 4 & 0 & 0 & 0 & 0 & 0 \\
\hline Defensores & 2 & 12 & 2 & 0 & 14 & 5 \\
\hline $\begin{array}{l}\text { Trans- } \\
\text { migrantes }\end{array}$ & 0 & 2 & 0 & 12 & 2 & 1 \\
\hline Ninguna & 0 & 1 & 0 & 1 & 1 & 0 \\
\hline Total & 8 & 23 & 13 & 16 & 61 & 10 \\
\hline
\end{tabular}

Fuente: Elaboración propia con base en los textos seleccionados de "El Universal".

* En el caso de que la noticia refiera la voz de dos o más actores sociales, sólo se tiene en cuenta el de más relevancia.

${ }^{* *}$ Se revisaron exclusivamente los ejemplares de periódico correspondientes a los meses impares. El año 2017 sólo incluye hasta el mes de julio. 


\section{Gráfica 1}

\section{Distribución porcentual de la presencia de los actores sociales* en los textos informativos sobre migración centroamericana en tránsito clandestino por \\ México, 2012-2017**}

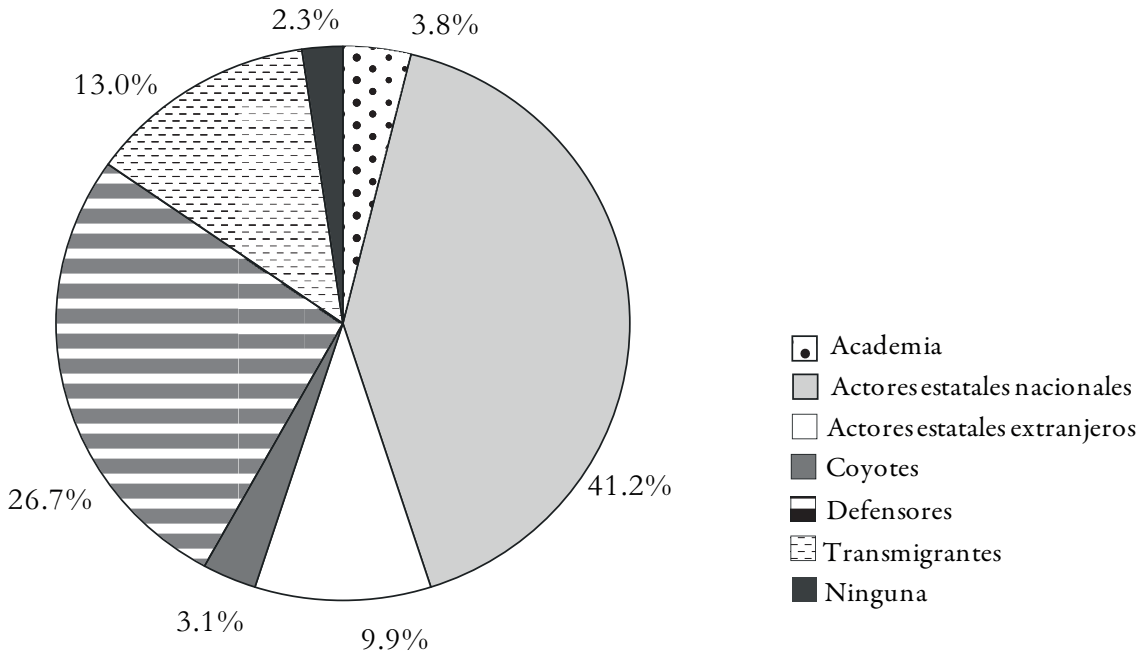

Fuente: Elaboración propia con base en los textos seleccionados de "El Universal".

* En el caso de que la noticia refiera la voz de dos o más actores sociales, sólo se tiene en cuenta el de más relevancia.

** Se revisaron exclusivamente los ejemplares de periódico correspondientes a los meses impares. El año 2017 sólo incluye hasta el mes de julio. 
Eduardo Torre-Cantalapiedra. De nacionalidad española, es Doctor en Estudios de Población por El Colegio de México y Licenciado en Ciencias de la Comunicación por la Universidad Rey Juan Carlos de Madrid. Actualmente es investigador postdoctoral en el Instituto de Investigaciones Jurídicas de la UNAM, asesorado por el doctor Enrique Mauricio Padrón Innamorato. Pertenece al Sistema Nacional de Investigadores (Nivel 1). UNAM. Líneas de investigación: migración internacional y políticas migratorias. Publicaciones recientes: en coautoría con Silvia E. Giorguli, “Movilidades internas e internacionales en Colombia: determinantes, patrones migratorios y diversidad de destinos, 1950-2010", en Revista Latinoamericana de Estudios de Población (RELAP), año 10, núm. 19, Brasil (2017); "Las respuestas mexicanas frente a la Ley Arizona y el rol de los estados en la gestión inmigratoria estadounidense", en Revista Mexicana de Ciencias Políticas y Sociales, año LXII, núm. 229, México (2017); "Participación de jóvenes mexicanos en DACA: un análisis exploratorio en perspectiva individual y familiar en dos contextos de políticas 'inmigratorias' contrastantes", en Huellas de la Migración, vol. 2, núm. 3, México (2017).

Recepción: 6 de marzo de 2018.

Aprobación: 10 de abril de 2018. 
